\title{
Retinoic Acid Promotes Mucosal and Systemic Immune Responses after Mucosal Priming and Systemic Boosting in Mice
}

\author{
Elisa Cirelli ${ }^{1,2}$, Antonella Riccomi ${ }^{1}$, Filippo Veglia ${ }^{2}$, Valentina Gesa ${ }^{1}$, Maria Teresa De Magistris ${ }^{1}$ and Silvia Vendetti $^{1^{*}}$ \\ ${ }^{1}$ Department of Infectious, Parasitic and Immune-mediated Diseases, Istituto Superiore di Sanità, Rome, Italy \\ 2Animal Breeding Department (STA), University of Rome "Tor Vergata", Rome, Italy
}

"Corresponding author: Dr. Silvia Vendetti, Department of Infectious, Parasitic and Immune-Mediated Diseases, Istituto Superiore di Sanità, Viale regina Elena 29900161 Rome, Italy, Tel: 39-06-49902734; Fax: 39-06-49902886; E-mail: silvia.vendetti@iss.it

Received date: 05 December 2014; Accepted date: 16 January 2015; Published date: 20 January 2015

Copyright: $\odot 2015$ Vendetti S, et al. This is an open-access article distributed under the terms of the Creative Commons Attribution License, which permits unrestricted use, distribution, and reproduction in any medium, provided the original author and source are credited.

\begin{abstract}
Objective: Few mucosal vaccines are available for human use, none of which are recombinant proteins or subunits of pathogens, owing to the lack of potent and safe mucosal adjuvants. Given the crucial role of retinoic acid (RA) in favouring dendritic cell differentiation, imprinting a mucosal homing capacity on $\mathrm{T}$ and $\mathrm{B}$ cells, as well as its potential to promote the differentiation of IgA-producing plasma cells, we evaluated the capacity of RA to improve mucosal vaccinations.
\end{abstract}

Study design: BALB/c mice were treated for eight days with RA or its vehicle and then intranasally immunized with tetanus toxoid (TT) with or without CT and boosted three times. Alternatively, mice treated with RA or its vehicle, were exposed to intranasal delivery of TT alone and boosted systemically with TT and Alum. Serum and mucosal Ag-specific antibody responses were examined 2 weeks and 8 months after the priming.

Results: Treatment with RA synergises with the adjuvant capacity of CT to enhance both systemic and mucosal TT-specific antibody responses. The combination of mucosal priming with $\mathrm{Ag}$ alone, followed by a boost with systemic adjuvant was also evaluated. Mice treated with RA showed a higher titer of mucosal IgA compared to untreated mice, after intranasal priming with TT followed by a systemic boost with TT plus Alum. After eight months, higher IgG TT-specific antibodies in the serum and a higher frequency of TT-specific IgG and IgA secreting cells were detected in the bone marrow of mice treated with RA as compared to untreated mice. Higher percentages of proliferating CD4 and CD8 T cells upon TT stimulation were found in the spleens, in the mesenteric lymph nodes and in the colonic lamina propria of mice treated with RA.

Conclusion: This approach induces mucosal immunity in the absence of mucosal adjuvants and improves the effectiveness of mucosally-delivered vaccine.

Keywords: Mucosal immunity; Retinoic acid; Cholera toxin; IgA; Mucosal immunization; Systemic immunization; Adjuvant; Mucosal adjuvant

\section{Introduction}

Majority of pathogenic viruses, bacteria and parasites as well as environmental allergens invades or enters the host through mucosal surfaces. The mucosal immune system has evolved to prevent colonization and invasion by harmful pathogens, therefore, stimulation of mucosal defences is very important for controlling infection and preventing diseases [1]. The development of mucosal vaccines targeted to induce protective immunity against a broad range of pathogens that can be acquired through mucosal or non-mucosal routes could have positive public health benefits. Mucosal immunization has been demonstrated to efficiently elicit humoral and cellular responses both locally and systemically, as observed in animal models and in humans [2,3]. Among the mucosal routes, the nasal route of immunization is very efficient at inducing humoral and cellular immune responses [4-7]. The nasal-associated lymphoid tissue (NALT) present in rodents, is an important inductive tissue for the generation of mucosal immunity to inhaled antigens and is capable of disseminating effector cells at distant sites $[8,9]$. It has been largely proved that the nasal route is effective in inducing memory immune responses both systemically and locally, i.e., in the respiratory, genital, and intestinal tracts [10-13]. Limitations to the use of the nasal route are generally related to the choice of adequate mucosal adjuvants and delivery systems whose potency needs to be carefully balanced with their potential toxicity [14,15]. Different adjuvants and delivery systems have been proposed for the development of effective nasal vaccines $[1,16]$, however to date a potent and safe mucosal adjuvant suitable for human use is still missing. Therefore, novel approaches to elicit mucosal immune responses are highly needed.

Retinoic Acid (RA) is an essential micronutrient with immunomodulatory capacity able to regulate tolerance and immunity at mucosal surfaces $[17,18]$. It has been reported that it directly controls $\mathrm{CD}^{+} \mathrm{T}$ cell immunity and differentiation towards Th1/Th17 polarization [18-20] and controls the homeostasis of DC at central lymphoid and mucosal tissues [21,22]. Given its crucial role in imprinting a mucosal homing capacity on $\mathrm{T}$ and $\mathrm{B}$ cells, and in inducing IgA-producing plasma cells [23-26], RA could improve mucosal vaccination protocols. Here, we show that treatment with RA synergises with the mucosal adjuvant Cholera Toxin (CT) enhancing 
both the systemic and mucosal tetanus specific antibody responses and that by combining intranasal delivery of Ag followed by systemic immunization with Alum, durable systemic and mucosal immune responses were induced.

\section{Materials and Methods}

\section{Media and reagents}

RPMI 1640 supplemented with $2 \mathrm{mM} \mathrm{L-glutamine,} \mathrm{1 \%} \mathrm{(v/v)}$ nonessential amino acids, $1 \%(\mathrm{v} / \mathrm{v})$ pyruvate, $55 \mu \mathrm{M} \quad 2$ mercaptoethanol $100 \mathrm{U} / \mathrm{ml}$ penicillin, $100 \mu \mathrm{g} / \mathrm{ml}$ streptomycin (Gibco, USA), and 10\% FCS (Hyclone Laboratories, USA), was used as complete medium in all cultures. Anti-CD3 (clone 145-2C11) monoclonal antibody $(\mathrm{mAb})$ was purchased from $\mathrm{BD}$ Pharmingen, San Diego CA, (USA). All trans Retinoic acid (RA) (R-2625) and sesame oil from Sigma-Aldrich, St. Louis, MO, Tetanus toxoid was kindly provided from Novartis (Italy), CT (\#100B) was purchased from List (USA) and Alum AH ALHYDrogel 2\% was purchased by InvivoGen (vac-alu).

Immunization schedules. Female BALB/c mice aged 6 to 8 weeks were obtained from Harlan Nossan, Italy and maintained in our animal facilities for the duration of the experiments. All animal procedures were in accordance with institutional guidelines. Groups (four or five) of mice were treated for eight days with RA ( $20 \mu \mathrm{g} / \mathrm{dose} /$ day) by subcutaneous injection at the base of the tale in $100 \mu \mathrm{l}$ of volume or its vehicle (sesame oil) and then intranasally immunized four times, at weekly intervals (days $0,7,14$ and 21), with $1 \mu \mathrm{g}$ of Tetanus Toxoid (TT) in the presence or in the absence of CT $(0.5 \mu \mathrm{g} /$ dose). Groups of untreated mice immunized with TT alone or TT in presence of CT were included as control. For intranasal immunization, mice were lightly anesthetized by intraperitoneal injection of ketamine hydrocloride (Ketavet, Gellini Pharmaceutics, $50 \mathrm{mg} / \mathrm{Kg}$ of weight) and xylazine (Rompun, Bayer, $3 \mathrm{mg} / \mathrm{Kg}$ of weight). A volume of 15 to $20 \mu$ (i.e., 7.5-10 $\mu \mathrm{l}$ per nostril) of a sterile phosphate-buffered saline (PBS) solution containing Ag, with or without adjuvant, was then administered. In the next experiments, groups of mice treated or untreated with RA for eight days, were intranasally immunized twice (at day 8 and 15) with TT alone and systemically boosted at day 22 with TT $(1 \mu \mathrm{g} / \mathrm{dose})$ in combination with Alum $(100 \mu \mathrm{l}$ via intraperitoneal (i.p.) injection. Serum samples and mucosal fluids from vaginal washes were collected 2 weeks after the boost and 8 months after the intranasal priming. Serum samples were obtained from blood collected from the retro-orbital plexus of anaesthetized mice and serum was stored at $-20^{\circ} \mathrm{C}$ until assayed. Vaginal washes were obtained by using $150 \mu \mathrm{l}$ of PBS, introducing $50 \mu \mathrm{l}$ at the time into the vaginal tract of mice using a Gilson pipette.

\section{Analysis of antibody isotypes}

All samples were tested by a standard enzyme-linked immunoabsorbant assay (ELISA). We coated 96-well plates (Greiner bio-one, Germany) with $0.5 \mu \mathrm{g} /$ well of TT overnight at $4^{\circ} \mathrm{C}$. After washing with PBS $0.05 \%$ (v/v) Tween 20 (UCS Diagnostics, Italy) and blocking for $2 \mathrm{~h}$ with $200 \mu \mathrm{l}$ of PBS containing $1 \%$ (v/v) bovine serum albumin (Sigma Aldrich, USA), serial dilutions of sera and secretions from individual mice were added to duplicate wells and incubated for $2 \mathrm{~h}$ at room temperature. The plates were then washed and biotinconjugated goat anti-mouse IgG (Sigma Aldrich, USA) or biotinconjugated goat anti-mouse IgA (Sigma Aldrich, USA) diluted 1:1000 in PBS-Tween 20 was then added to the wells for $2 \mathrm{~h}$ at room temperature. The plates were washed before addition of horse radish peroxidase HRP-conjugated streptavidin (Dako, Italy) diluted 1:2000 in PBS-Tween for 30 minutes at room temperature. Finally, after washing with PBS-Tween, the Ag-antibody reaction was measured by using the 3.3, 5.5 -tetramethylbenzidine substrate (Kirkegaard \& Perry Laboratories, USA). The colour reaction was terminated after 5 to 10 minutes with $50 \mu \mathrm{l}$ of $0.2 \mathrm{M} \mathrm{H} 2 \mathrm{SO}$. Endpoint titers were determined as thereciprocal of the highest dilution giving an absorbance of more than 0.3 units (for $\operatorname{IgG}$ ) and 0.2 units (for $\operatorname{IgA}$ ) than the negative controls.

Evaluation of antibody secreting cells (ASC). Cells were obtained from bone marrow by syringe insertion into one end of the bone and flushing with RPMI medium. Single cell suspensions from bone marrow were transferred on tubes containing complete medium RPMI 1640 , containing $10 \%$ fetal bovine serum (FBS) (Euroclone, Life Sciences Division, Milan, Italy), 100 units/ml of penicillinstreptomycin-glutamine (Gibco Invitrogen, Paisley, UK), nonessential aminoacids (Gibco), sodium pyruvate $1 \mathrm{mM}$ (Euroclone), HEPES buffer solution $25 \mathrm{mM}$ (Euroclone) $50 \mu \mathrm{M}$ 2-mercaptoethanol (Sigma Chemicals, Co., St. Louis, MO, USA). BM cells derived from mice of the same group were pooled and assayed for frequencies of specific antibody secreting cells (ASC) by the ELISPOT assay. Briefly, $2 \times 10^{5}$ cells/well were incubated over night at $37^{\circ} \mathrm{C}$ in PVDF 96-well plates (Millipore) previously coated with TT $(20 \mu \mathrm{g} / \mathrm{ml})$. Plates were then extensively washed and wells were developed by stepwise incubations with HRP-conjugated goat antibodies to mouse IgG and IgA (Sigma Chemicals, Co., St. Louis, MO, USA) followed by amino ethyl-carbazole chromogenic substrate (Sigma Chemicals, Co., St. Louis, MO, USA). Spots were enumerated using an automated reader (A.EL.VIS, Hannover, Germany).

\section{Isolation and culture of murine colonic lamina propria mononuclear cells}

Colonic lamina propria mononuclear cells (LPMC) were isolated from freshly obtained colonic tissues using a modification of the technique described by Van der Heijden and Stok [27]. The colonic tissues were initially washed in HBSS-calcium-magnesium free (HyClone Europe, Cramlington, U.K.), cut into $0.5-\mathrm{cm}$ pieces, and incubated in HBSS containing $0.75 \mathrm{mmol} / \mathrm{L}$ EDTA and $1 \mathrm{mmol} / \mathrm{L}$ DTT (Sigma) at $37^{\circ} \mathrm{C}$ for $15 \mathrm{~min}$ for two cycles. The tissue was then digested further in RPMI 1640 (HyClone) containing $400 \mathrm{U} / \mathrm{ml}$ collagenase D and $0.01 \mathrm{mg} / \mathrm{ml}$ DNase I (Boehringer Mannheim, Indianapolis, IN) in a shaking incubator at $37^{\circ} \mathrm{C}$. The LPMC released from the tissue were then re-suspended in 100\% Percoll, layered under a $40 \%$ Percoll gradient (Pharmacia Biotech), and then subjected to centrifugation to obtain the lymphocyte enriched population at the 40-100\% Percoll interface.

Proliferation assays. Spleens and lymph nodes were removed from the mice and single cell suspensions obtained by passing organs through a $100 \mu \mathrm{m}$-pore-size nylon cell strainer (BD, USA). Single cell suspensions from two mice per group were pooled together. After lysis of erythrocytes, cells $(107 / \mathrm{ml})$ were washed in PBS $1 \%$ (v/v) FCS and incubated with $2.5 \mu \mathrm{M}$ of carboxyfluorescein succinimidyl ester (CFSE, Molecular probes, Eugene, USA) for $10 \mathrm{~min}$ at $37^{\circ} \mathrm{C}$. The reaction was quenched by the addition of ten volumes of cold RPMI $10 \%(\mathrm{v} / \mathrm{v})$ FCS and incubating for $5 \mathrm{~min}$ at $4^{\circ} \mathrm{C}$. Cells $\left(3 \times 10^{6} / \mathrm{ml}\right.$ for spleens and mesenteric lymph nodes and the approximately $1 \times 10^{6}$ cells from the colonic lamina propria digestion) were washed three times with RPMI 10\% (v/v) FCS cultured at 105/well in 96 well plate, 
stimulated with TT $(1 \mu \mathrm{g} / \mathrm{ml})$ or anti-CD3 mAbs $(0.1 \mu \mathrm{g} / \mathrm{ml})$. After 5 days, cells were stained with anti-CD4-PE (clone GK1.5), anti-CD8-PE (clone 57-6.7) and anti-B220-PECy5 (clone RA3-6B2) mAbs and acquired on a FACSCaliburTM instrument running CellQuest software and analysed by Flowjo software.

\section{Results}

\section{Treatment with RA enhances systemic and mucosal tetanus- specific antibody responses}

To evaluate the capacity of RA to improve mucosal vaccination, groups of $\mathrm{BALB} / \mathrm{c}$ mice were first treated for eight days with RA (20 $\mu \mathrm{g} /$ dose/day) by subcutaneous injection or its vehicle (sesame oil) and then intranasally immunized with TT $(1 \mu \mathrm{g} /$ dose $)$ in the presence or absence of $0.5 \mu \mathrm{g} / \mathrm{dose}$ of CT and boosted three times. Groups of untreated mice immunized with TT alone or TT in presence of CT were included as controls. Serum Ag-specific antibody responses were examined one week after the fourth immunization and the anti-TT IgG levels were higher in mice treated with $\mathrm{RA}$ as compared to mice treated with the vehicle $(p=0.027$, number of mice $=5)$ (Figure $1 \mathrm{~A})$. Anti-TT specific IgA antibodies were also detected after four immunizations in the vaginal washes of mice and the levels were significantly higher in mice treated with RA as compared to mice treated with the vehicle $(\mathrm{p}=0.018$, number of mice $=5$ ) (Figure $1 \mathrm{~B})$. No differences were observed in IgG or IgA levels between untreated mice and mice treated with vehicle alone (Figure 1). Of note, in this set of experiments, we observed an increase of TT-specific IgA responses after intranasal administration of the Ag alone in the absence of CT in RA treated as compared to vehicle-treated or untreated mice $(p=0.009$, number of mice $=5$ ). Therefore, we asked weather it could be possible to further amplify mucosal immune response using a combination of mucosal priming with $\mathrm{Ag}$ alone, followed by a boost with systemic adjuvant in mice treated with RA. Groups of BALB/c mice treated for a week with RA $(20 \mu \mathrm{g} /$ dose/day) or its vehicle (sesame oil) were exposed twice, a week a part, to intranasal delivery of TT alone and boosted systemically (i.p) with TT and Alum. After 2 weeks serum and mucosal Ag-specific antibody responses were examined (Figure 2). The levels of serum TT-specific IgG was amplified after the boost in all groups and even if the titer appears higher in mice treated with RA no significantly differences were found between the groups $(p=0.085$, number of mice $=8$ ) (Figure 3A). However, higher anti-TT specific IgA antibodies titer was detected in the vaginal washes of mice treated with $\mathrm{RA}$ as compared to mice untreated or treated with the vehicle $(\mathrm{p}=0.0002$, number of mice $=8$ ) (Figure $3 \mathrm{~B})$. These data suggest that increased mucosal immune responses can be induced in mice treated with RA by delivering Ag alone intranasally and boosting with a systemic adjuvant.

Persistence of systemic IgG response and higher IgG and IgA antibody secreting cells in the bone marrow of mice treated with RA in order to evaluate the persistence of Ag-specific antibodies in mice treated for eight days with RA ( $20 \mu \mathrm{g} /$ dose/day) or its vehicle, exposed to intranasal delivery of TT alone and boosted systemically (i.p) with TT and Alum, serum and mucosal anti-TT IgG and IgA antibodies were analysed 8 months after the intranasal priming. As shown in Figure 3C, TT-specific IgG decreased after the systemic boost, but they were still present up to 8 months and the titer was significantly higher in mice treated with RA as compared with control groups ( $\mathrm{p}=0.02$, number of mice $=4$ ). At this time point the $\operatorname{IgA}$ titer decreased in all groups of mice (Figure 3D), but still differences were observed between RA treated versus untreated mice $(107 \pm 52$ vs. $38 \pm 13)$. However, to verify whether either IgG or IgA long living plasma cells were induced following immunization, the presence of TT-specific antibody secreting cells (ASC) was analysed in bone marrows of mice after 8 months by ELISPOT assay. As shown in Figure 4, higher number of anti-TT IgG ASC was found in bone marrow of mice treated with RA as compared to vehicle treated mice $(420 \pm 28$ and 180 $\pm 28 \mathrm{ASC} / 1 \times 10^{6}$ cells, respectively, $\left.\mathrm{p}<0.05\right)$ Figure $5 \mathrm{~A}$. In addition, anti-TT IgA ASC were detected in bone marrow of immunized mice treated with RA as compared to control mice $(90 \pm 14$ and $5 \pm 7$ ASC/ $1 \times 10^{6}$ cells, respectively, $\mathrm{p}<0.05$ ) (Figure $4 \mathrm{~B}$ ). These data suggest that in presence of RA treatment the response induced by a combination of mucosal priming with $\mathrm{Ag}$ followed by a boost with systemic adjuvant, in the absence of a mucosal adjuvant, is sustained and durable.
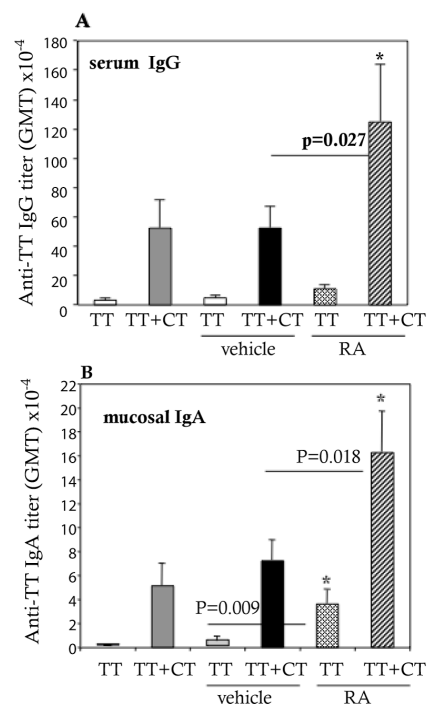

Figure 1: Serum IgG (A) and vaginal IgA (B) responses to TT (1 $\mu \mathrm{g} /$ dose) in BALB/c mice treated or untreated for 8 days with RA (20 $\mu \mathrm{g} /$ dose/day) or its vehicle (sesame oil), intranasally immunized with TT $(1 \mu \mathrm{g} /$ dose $)$ in the presence or in the absence of CT $(0.5 \mu \mathrm{g} /$ dose) four times. Results are expressed as the IgG or IgA geometric mean titer (GMT). The anti-TT IgG titer was determined in sera and the anti-TT specific IgA in vaginal washes collected one week after fourth immunization. Bars indicate the SEM and stars $\left(^{*}\right)$ indicate that the differences between the group treated with RA and the groups treated with RA-vehicle or untreated mice are significant.

Numbers indicate the percentage of proliferating cells, which diluted CFSE upon TT or aCD3 stimulation among the CD4 $4^{+}, \mathrm{CD} 8^{+}$ or $\mathrm{B}_{2} 20^{+}$gated-population. Hystograms (C) show the percentage of the proliferative capacity upon TT stimulation in the spleens (leftt) and in the mesenteric lymph nodes (right). Bars indicate the SEM of three independent experiments and stars $\left(^{*}\right)$ indicate that the differences between the group treated with RA and its vehicle are significant $(\mathrm{p}<0.05)$. 


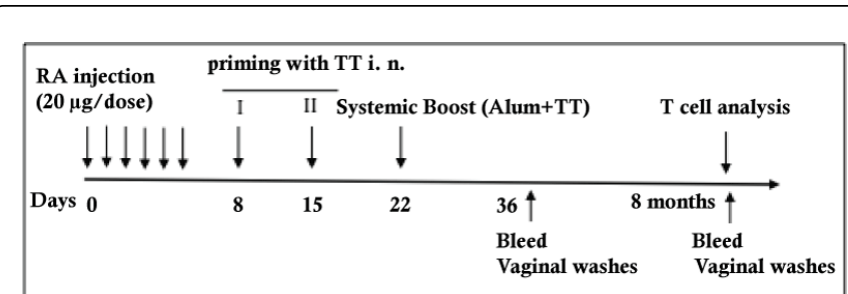

Figure 2: Immunization schedule of $\mathrm{BALB} / \mathrm{c}$ mice treated or untreated for 8 days with RA $(20 \mu \mathrm{g} /$ dose/day $)$ or its vehicle (sesame oil), intranasally immunized with TT $(1 \mu \mathrm{g} / \mathrm{dose})$ and sistemically (i.p.) boosted with Ag in presence of Alum.
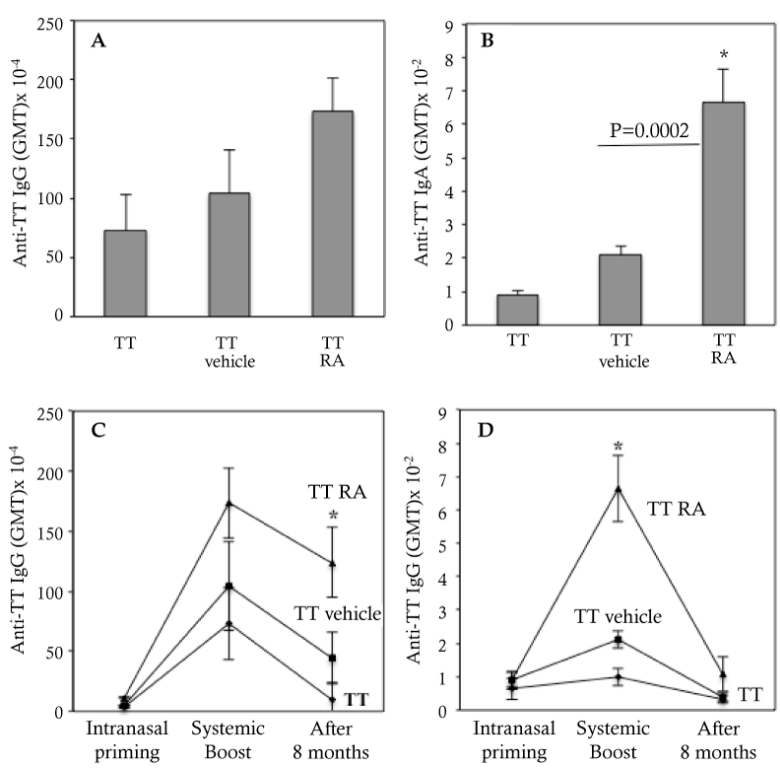

Figure 3: Longitudinal analysis of serum IgG (A-C) and vaginal IgA (B-D) responses to TT $(1 \mu \mathrm{g} / \mathrm{dose})$ in $\mathrm{BALB} / \mathrm{c}$ mice treated or untreated for 8 days with RA $(20 \mu \mathrm{g} /$ dose/day $)$ or its vehicle (sesame oil), intranasally immunized with TT $(1 \mu \mathrm{g} /$ dose $)$ and sistemically (i.p.) boosted with $\mathrm{Ag}$ in presence of Alum. Results are expressed as the IgG or IgA geometric mean titer (GMT). The antiTT IgG titer was determined in sera and the anti-TT specific IgA in vaginal washes collected two weeks after the systemic immunization and two weeks and 8 months after mucosal priming. Bars indicate the SEM and stars $\left(^{*}\right)$ indicate that the differences between the group treated with RA and the groups treated with its vehicle or untreated mice are significant.

\section{Analysis of T cell response}

To determine the capacity of T lymphocytes to proliferate upon $\mathrm{Ag}$ stimulation, 8 months after the intranasal priming, spleen and mesenteric lymph nodes, which are draining lymph nodes of mucosal tissues, were processed and cells utilized in proliferation assay. Both the proliferative capacity upon $\mathrm{Ag}$ re-stimulation of $\mathrm{CD} 4^{+}$and $\mathrm{CD} 8^{+} \mathrm{T}$ cells were analysed by labeling splenocytes and lymph node derived cells with CFSE. The percentage of proliferating cells was calculated within the $\mathrm{CD}^{+}$or $\mathrm{CD}^{+}$gated populations. Cells stimulated with
anti-CD3 mAb were included as positive control and showed a marked proliferative response (ranging between $80 \%$ and $100 \%$ of $\mathrm{T}$ cell proliferation, Figure 5). As shown in Figure 4, mice treated with RA showed a higher proliferation of $\mathrm{CD}^{+}$and $\mathrm{CD} 8^{+} \mathrm{T}$ cells upon TT stimulation as compared to mice treated with vehicle in both spleen and in mucosal draining lymph nodes $(\mathrm{p}<0.05)$. A higher percentage of proliferating B $220^{+}$cells was also observed in the districts analysed.
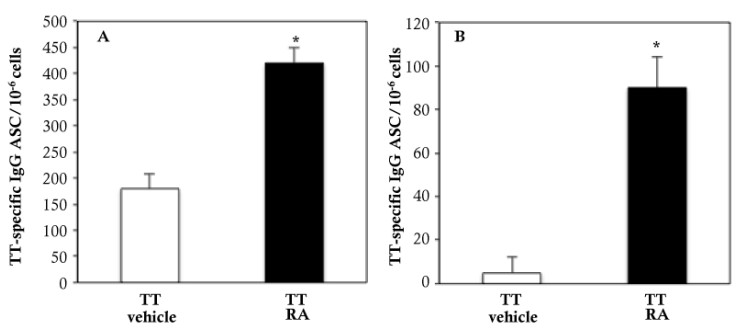

Figure 4: Antigen-specific long living plasma cells in the bone marrows of $\mathrm{BALB} / \mathrm{c}$ mice treated or untreated for 8 days with RA $(20 \mu \mathrm{g} /$ dose/day) or its vehicle (sesame oil), intranasally immunized with TT $(1 \mu \mathrm{g} /$ dose) and sistemically (i.p.) boosted with Ag in presence of Alum after 8 months. Tetanus-specific $\operatorname{IgG}(\mathrm{A})$ and $\operatorname{IgA}$ (B) antibody secreting cells (ASC) were analysed by ELISPOT assay. Bars indicate the SEM of three independent experiments and stars $\left(^{*}\right)$ indicate that the differences between the group treated with RA and its vehicle are significant $(\mathrm{p}<0.05)$.

To assess whether $\mathrm{CD}^{+}$and $\mathrm{CD}^{+} \mathrm{T}$ lymphocytes capable to respond to the Ag stimulation, were able to colonize the mucosal compartments, cells isolated from the colonic lamina propria of immunized mice treated with RA or its vehicle were labelled with CFSE and stimulated with TT for 3 days. Cells stimulated with anti$\mathrm{CD} 3 \mathrm{mAb}$ were included as positive control and showed a marked proliferative response Figure 6 . The percentage of proliferating cells was calculated within the $\mathrm{CD} 4^{+}$or $\mathrm{CD}^{+}$gated populations and as shown in Figure 6, only cells from mice treated with RA showed CD4 and CD8 proliferation after in vitro re-stimulation with TT, suggesting a mucosal colonization of $\mathrm{T}$ lymphocytes specific for the Ag, following RA treatment (i.p.) boosted with $\mathrm{Ag}$ in presence of Alum. After 8 months cells collected from the colonic lamina propria were cultured in vitro in the presence or in the absence of TT $(1 \mu \mathrm{g} / \mathrm{ml})(\mathrm{B}-\mathrm{C}, \mathrm{G}-\mathrm{H})$ or anti-CD3 $(0.1 \mu \mathrm{g} / \mathrm{ml})(\mathrm{D}-\mathrm{E}, \mathrm{I}-\mathrm{L})$ for 5 days and the response was evaluated by CFSE assay. To evaluate CD4+ and $\mathrm{CD}^{+} \mathrm{T}$ cell proliferation, cells were labelled with CFSE, cultured in vitro as described, stained with fluorocrome conjugated anti-CD4 and anti$\mathrm{CD} 8 \mathrm{mAb}$ and analyzed by flow cytometry. The percentage of proliferating cells was calculated among the $\mathrm{CD}^{+}, \mathrm{CD}^{+}$gated population. Numbers indicate the percentage of cells which diluted CFSE upon stimulation.

\section{Discussion}

An effective and safe mucosal adjuvant to be used in combination with recombinant proteins or subunits of pathogens, is still missing. We evaluated the capacity of vitamin A metabolites (RA) to improve mucosal vaccinations. First, we found that treatment with RA enhanced systemic and mucosal Ag-specific antibody responses elicited by intranasal administration of TT and the experimental mucosal adjuvant CT. Thereafter, by using a combination of mucosal 
Page 5 of 7

priming with Ag, followed by a boost with systemic adjuvant, we found increased and durable systemic and mucosal immune responses in mice treated with RA. The advantage of this vaccine strategy would be to induce mucosal immunization avoiding the use of mucosal adjuvants, which are not yet available. Indeed, besides CT and the Escherichia coli heat-labile enterotoxin (LT) and they derivatives, few substances have proven to be as effective as mucosal adjuvants in experimental animal model $[1,28,29]$. Because of the toxicity of CT and LT and the reported side effects after intranasal administration of LT, their clinical use is unlikely [14-15,30]. Here, by delivering intranasally the Ag alone followed by a systemic boost with Ag plus Alum, we observed a titer of $\operatorname{IgA}$ in the vaginal compartment comparable to that elicited by using full immunization schedule with CT. Alum is largely used as systemic adjuvant, however, it induces poor mucosal immunization $[31,32]$, therefore the approach described here, could be useful to redirect the immune responses to mucosal compartments. The possible advantages of this vaccination procedure would be that systemic adjuvants currently used could be employed to induce mucosal immune responses.

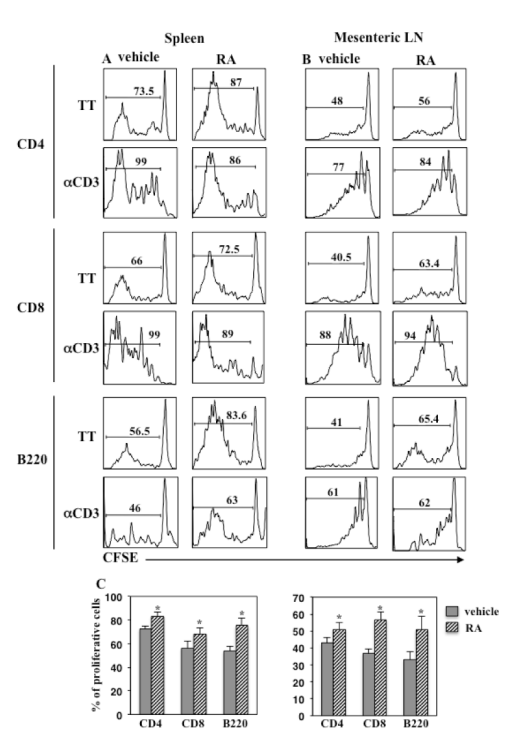

Figure 5: Proliferating $\mathrm{CD}^{+}, \mathrm{CD}^{+}$and $\mathrm{B} 220^{+}$cells upon TT stimulation from $\mathrm{BALB} / \mathrm{c}$ mice treated or untreated with RA (20 $\mu \mathrm{g} /$ dose/day) or its vehicle (sesame oil), intranasally immunized with TT $(1 \mu \mathrm{g} /$ dose $)$ and sistemically (i.p.) boosted with TT and Alum. After 8 months cells collected from spleens (A) and mesenteric lymph nodes (B) were cultured in vitro in the presence or in the absence of TT $(1 \mu \mathrm{g} / \mathrm{ml})$ or anti-CD3 ( $\alpha \mathrm{CD} 3) \mathrm{mAb}$ for 5 days and the proliferating cells were detected by CFSE assay. Cells were labelled with CFSE, cultured in vitro as described, stained with fluorocrome conjugated anti-CD4, anti-CD8 or anti-B220 mAb and analyzed by flow cytometry.

Retinoic acid is an important factor for promoting mucosal immunity, due to its capability to directly induce the mucosal homing receptors $\alpha 4 \beta 7$ and CCR9 on both T and B cells [23-26]. These studies support the hypothesis that RA promotes mucosal immunity by controlling the trafficking of responding cells. Indeed, we found proliferating $\mathrm{CD}^{+}$and $\mathrm{CD}^{+} \mathrm{T}$ cells upon $\mathrm{Ag}$ stimulation in the colonic lamina propria of vaccinated mice treated with RA. These findings are consistent with other studies showing that RA given at the time of vaccination has the capacity to increase the accumulation of memory cells in the gut mucosa [32,33]. We hypothesize that by administrating RA to mice during vaccination, Ag-specific $\mathrm{T}$ cells expressing mucosal homing receptors were generated, these cells in turn migrated to mucosal tissues, this could explain the presence of $\mathrm{CD} 4$ and $\mathrm{CD} 8$ that were activated by Ag restimulation. Furthermore, RA signalling on $B$ cells results in the induction of IgA via enhancement of class switching to IgA [24,34-36].

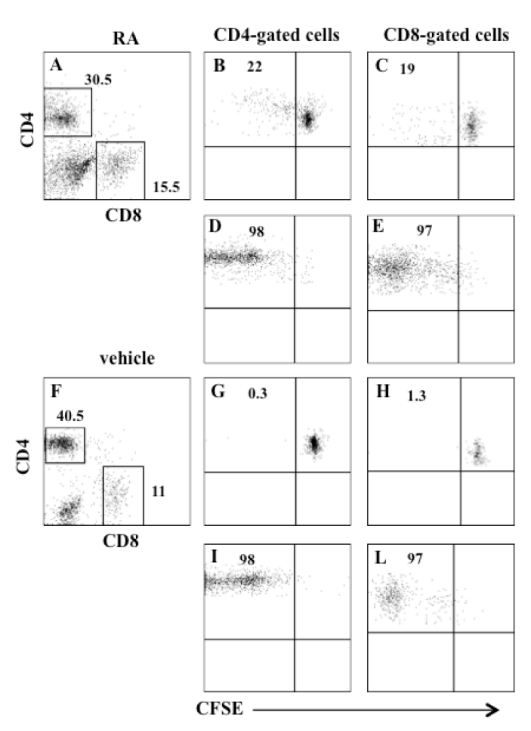

Figure 6: Percentage of proliferating $\mathrm{CD}^{+}$and $\mathrm{CD}^{+} \mathrm{T}$ cells from the colonic lamina propria of $\mathrm{BALB} / \mathrm{c}$ mice treated for 8 days with RA (20 $\mu \mathrm{g} /$ dose/day) (A-E) or its vehicle (sesame oil) (F-L), intranasally immunized with TT $(1 \mu \mathrm{g} /$ dose $)$ and systemically.

This is in agreement with our finding that an increased titer of IgA was found in the vaginal washes of immunized mice. However, while we found persistent high levels of IgA secreting cells in the bone marrow of mice immunized in presence of RA as compared to untreated mice, we observed a decrease of IgA titers in vaginal washes of the same mice after 8 months. This could be explained by a different assay used to detect the capacity to produce IgA. Indeed, whereas in the bone marrow we measured the presence of antibody secreting cells by Elispot upon in vitro Ag re-stimulation, in the vaginal washes we measured the IgA titre by ELISA in the absence of Ag re-stimulation. Both evaluations were performed after 8 months, when probably the memory cells were quiescent. More studies will be done to address whether the presence of bone marrow IgA ASC correlates with mucosal immune response following in vivo $\mathrm{Ag}$ re-stimulation. Furthermore, RA has been described to have a more general role in promoting both humoral and cellular immunity at mucosal and peripheral sites [25,37]. Indeed, impaired $\mathrm{T}$ cell activation and differentiation occurs in mucosal as well as in peripheral tissues in the absence of RA-mediated signalling [18-20,25,38,39]. Furthermore, it is essential in controlling splenic and mucosal dendritic cell homeostasis and differentiation $[21,40]$. All these functions give some explanation for the profound immune deficiencies associated with increased susceptibility to infections and poor vaccine responses observed in vitamin A deficiencies [40-42]. On the other hand, according with a multifactorial role played by RA on regulating systemic and mucosal immune responses we could explain the effect of RA treatment in 
maintaining longer and sustained systemic and mucosal responses to vaccine immunization. Indeed, we show that a persistence of systemic IgG response and higher IgG and IgA antibody secreting cells in the bone marrow of mice treated with RA. However, additional studies are needed to fully understand the mechanisms underlining vitamin A metabolism and signalling in controlling the differentiation and the regulation of immune responses.

The effect of vitamin A supplementation on vaccine efficacy has been evaluated in different studies and has generated disparate results [43] according to the type of vaccine and the target populations $[44,45]$. However, given the expanded knowledge of RA in regulating immunity it will be important to further understand the role of RA in clinical settings. Here, mice were treated for eight days with RA prior to vaccination in order to create the right environment, which could address cells towards the mucosal compartments. We are aware that is not practical for use in human vaccines as it is, however it could be developed into more practical application, in particular due to its hydrophobic composition, RA could be delivered in lyposome-like particles, which could incorporate also the vaccine, this approach is currently under investigation.

\section{Conclusion}

Our work shows that RA supplementation is able to potentiate mucosal and systemic vaccine induced immune responses as well as can contribute to elicit mucosal immunity in the absence of mucosal adjuvants or improve the effectiveness of mucosally-delivered vaccine.

\section{Acknowledgments}

The research leading to these results has received funding from the European Union's Seventh Framework Programme (FP7/2007-2013) under Grant Agreement 280873 ADITEC. We thank Dr. Ragnar Lindstedt for helpful discussions and critical reading of the manuscript and Antonio Di Virgilio for animal assistance.

\section{References}

1. De Magistris MT (2006) Mucosal delivery of vaccine antigens and its advantages in pediatrics. Adv Drug Deliv Rev 58: 52-67.

2. Holmgren J, Czerkinsky C (2005) Mucosal immunity and vaccines. Nat Med 11: S45-53.

3. Lycke N (2012) Recent progress in mucosal vaccine development: potential and limitations. Nat Rev Immunol 12: 592-605.

4. Kurono Y, Yamamoto M, Fujihashi K, Kodama S, Suzuki M, et al. (1999) Nasal immunization induces Haemophilus influenzae-specific Th1 and Th2 responses with mucosal IgA and systemic IgG antibodies for protective immunity. J Infect Dis 180: 122-132.

5. Wu HY, Russell MW (1997) Nasal lymphoid tissue, intranasal immunization, and compartmentalization of the common mucosal immune system. Immunol Res 16: 187-201.

6. Asanuma H, Fujihashi K, Miyakoshi T, Yoshikawa T, Fujita-Yamaguchi $\mathrm{Y}$, et al. (2007) Long- and short-time immunological memory in different strains of mice given nasally an adjuvant-combined nasal influenza vaccine. Vaccine 25: 6975-6980.

7. Olive C, Sun HK, Ho MF, Dyer J, Horváth A, et al. (2006) Intranasal administration is an effective mucosal vaccine delivery route for selfadjuvanting lipid core peptides targeting the group A streptococcal M protein. J Infect Dis 194: 316-324.

8. Kiyono H, Fukuyama S (2004) NALT- versus Peyer's-patch-mediated mucosal immunity. Nat Rev Immunol 4: 699-710.
9. Harandi AM, Medaglini D (2010) Mucosal adjuvants. Curr HIV Res 8: 330-335.

10. Zuercher AW (2003) Upper respiratory tract immunity. Viral Immunol 16: 279-289.

11. Neutra MR, Kozlowski PA (2006) Mucosal vaccines: the promise and the challenge. Nat Rev Immunol 6: 148-158.

12. Ciabattini A, Pettini E, Arsenijevic S, Pozzi G, Medaglini D (2010) Intranasal immunization with vaccine vector Streptococcus gordonii elicits primed CD4+ and CD8+ T cells in the genital and intestinal tracts. Vaccine 28: 1226-1233.

13. Ciabattini A, Pettini E, Fiorino F, Prota G, Pozzi G, et al. (2011) Distribution of primed $\mathrm{T}$ cells and antigen-loaded antigen presenting cells following intranasal immunization in mice. PLoS One 6: e19346.

14. Couch RB (2004) Nasal vaccination, Escherichia coli enterotoxin, and Bell's palsy. N Engl J Med 350: 860-861.

15. Lewis DJ, Huo Z, Barnett S, Kromann I, Giemza R, et al. (2009) Transient facial nerve paralysis (Bell's palsy) following intranasal delivery of a genetically detoxified mutant of Escherichia coli heat labile toxin. PLoS One 4: e6999.

16. Harandi AM, Sanchez J, Eriksson K, Holmgren J (2003) Recent developments in mucosal immunomodulatory adjuvants. Curr Opin Investig Drugs 4: 156-161.

17. Mora JR, Iwata M, von Andrian UH (2008) Vitamin effects on the immune system: vitamins A and D take centre stage. Nat Rev Immunol 8: 685-698.

18. Hall JA, Grainger JR, Spencer SP, Belkaid Y (2011) The role of retinoic acid in tolerance and immunity. Immunity 35: 13-22.

19. Hall JA, Cannons JL, Grainger JR, Dos Santos LM, Hand TW, et al. (2011) Essential role for retinoic acid in the promotion of CD4(+) T cell effector responses via retinoic acid receptor alpha. Immunity 34: 435-447.

20. Pino-Lagos K, Guo Y, Brown C, Alexander MP, Elgueta R, et al. (2011) A retinoic acid-dependent checkpoint in the development of CD4+ T cellmediated immunity. J Exp Med 208: 1767-1775.

21. Klebanoff CA, Spencer SP, Torabi-Parizi P, Grainger JR, Roychoudhuri $\mathrm{R}$, et al. (2013) Retinoic acid controls the homeostasis of pre-cDCderived splenic and intestinal dendritic cells. J Exp Med 210: 1961-1976.

22. Evans TI, Reeves RK (2013) All-trans-retinoic acid imprints expression of the gut-homing marker $\hat{\mathrm{I}} \pm 4 \hat{\mathrm{I}}^{2} 7$ while suppressing lymph node homing of dendritic cells. Clin Vaccine Immunol 20: 1642-1646.

23. Iwata M, Hirakiyama A, Eshima Y, Kagechika H, Kato C, et al. (2004) Retinoic acid imprints gut-homing specificity on $\mathrm{T}$ cells. Immunity 21 : 527-538.

24. Mora JR, Iwata M, Eksteen B, Song SY, Junt T, et al. (2006) Generation of gut-homing IgA-secreting B cells by intestinal dendritic cells. Science 314: 1157-1160.

25. Spencer SP, Belkaid Y (2012) Dietary and commensal derived nutrients: shaping mucosal and systemic immunity. Curr Opin Immunol 24: 379-384.

26. Ross AC (2012) Vitamin A and retinoic acid in T cell-related immunity. Am J Clin Nutr 96: 1166S-72S.

27. Boirivant M, Fuss IJ, Ferroni L, De Pascale M, Strober W (2001) Oral administration of recombinant cholera toxin subunit B inhibits IL-12mediated murine experimental (trinitrobenzene sulfonic acid) colitis. J Immunol 166: 3522-3532.

28. Eriksson K, Holmgren J (2002) Recent advances in mucosal vaccines and adjuvants. Curr Opin Immunol 14: 666-672.

29. Moyle PM, McGeary RP, Blanchfield JT, Toth I (2004) Mucosal immunisation: adjuvants and delivery systems. Curr Drug Deliv 1: 385-396.

30. Mutsch M, Zhou W, Rhodes P, Bopp M, Chen RT, et al. (2004) Use of the inactivated intranasal influenza vaccine and the risk of Bell's palsy in Switzerland. N Engl J Med 350: 896-903.

31. Chen K, Cerutti A (2010) Vaccination strategies to promote mucosal antibody responses. Immunity 33: 479-491. 
Citation: Cirelli E, Riccomi A, Veglia F, Gesa V, De Magistris MT, et al. (2015) Retinoic Acid Promotes Mucosal and Systemic Immune Responses after Mucosal Priming and Systemic Boosting in Mice. J Vaccines Vaccin 6: 265. doi:10.4172/2157-7560.1000265

Page 7 of 7

32. Tan X, Sande JL, Pufnock JS, Blattman JN, Greenberg PD (2011) Retinoic acid as a vaccine adjuvant enhances CD8+ $\mathrm{T}$ cell response and mucosal protection from viral challenge. J Virol 85: 8316-8327.

33. Hammerschmidt SI, Friedrichsen M, Boelter J, Lyszkiewicz M, Kremmer E, et al. (2011) Retinoic acid induces homing of protective T and B cells to the gut after subcutaneous immunization in mice. J Clin Invest 121 : 3051-3061.

34. Mora JR, Iwata M, von Andrian UH (2008) Vitamin effects on the immune system: vitamins A and D take centre stage. Nat Rev Immunol 8: 685-698.

35. Mora JR, von Andrian UH (2008) Differentiation and homing of IgAsecreting cells. Mucosal Immunol 1: 96-109.

36. Ma Y, Ross AC (2009) Toll-like receptor 3 ligand and retinoic acid enhance germinal center formation and increase the tetanus toxoid vaccine response. Clin Vaccine Immunol 16: 1476-1484.

37. Chen Q, Mosovsky KL, Ross AC (2011) Retinoic acid and Îtgalactosylceramide differentially regulate $\mathrm{B}$ cell activation in vitro and augment antibody production in vivo. Clin Vaccine Immunol 18: 1015-1020.

38. Surman SL, Jones BG, Rudraraju R, Sealy RE, Hurwitz JL (2014) Intranasal administration of retinyl palmitate with a respiratory virus vaccine corrects impaired mucosal IgA response in the vitamin A deficient host. Clin Vaccine Immunol 21: 598-601.
39. Spencer SP, Wilhelm C, Yang Q, Hall JA, Bouladoux N, et al. (2014) Adaptation of innate lymphoid cells to a micronutrient deficiency promotes type 2 barrier immunity. Science 343: 432-437.

40. Kaufman DR, De Calisto J, Simmons NL, Cruz AN, Villablanca EJ, et al. (2011) Vitamin A deficiency impairs vaccine-elicited gastrointestinal immunity. J Immunol 187: 1877-1883.

41. Cassani B, Villablanca EJ, De Calisto J, Wang S, Mora JR (2012) Vitamin $\mathrm{A}$ and immune regulation: role of retinoic acid in gut-associated dendritic cell education, immune protection and tolerance. Mol Aspects Med 33: 63-76.

42. Rudraraju R, Surman SL, Jones BG, Sealy R, Woodland DL, et al. (2012) Reduced frequencies and heightened CD103 expression among virusinduced CD8(+) $\mathrm{T}$ cells in the respiratory tract airways of vitamin Adeficient mice. Clin Vaccine Immunol 19: 757-765.

43. Savy M, Edmond K, Fine PE, Hall A, Hennig BJ, et al. (2009) Landscape analysis of interactions between nutrition and vaccine responses in children. J Nutr 139: 2154S-218S.

44. Benn CS (2012) Combining vitamin A and vaccines: convenience or conflict? Dan Med J 59: B4378.

45. Lisulo MM, Kapulu MC, Banda R, Sinkala E, Kayamba V, et al. (2014) Adjuvant potential of low dose all-trans retinoic acid during oral typhoid vaccination in Zambian men. Clin Exp Immunol 175: 468-475. 